\title{
Representaciones de la memoria religiosa en el movimiento de los focolares
}

institucional.us.es/ambitos/

\section{Agustina Adela Zaros}

Universidad de Padova (UNIPD)

agustinaadela.zaros@studenti.unipd.it

agostinazaros@gmail.com

English Version: The memories of the folocares movement, a religious portrayal

\section{Resumen}

El trabajo surge de una investigación doctoral que se ocupa de la transmisión religiosa en familias y miembros del Movimiento de los Focolares con el utilizo de metodología cualitativa.

La perspectiva analítica se refiere a la religión como memoria (Hervieu-Léger, 1993) en la reinterpretación de cada generación como continuidad entre el pasado y el presente, en la relación

entre lo simbólico y sus prácticas; con los conflictos generacionales de la socialización religiosa de una línea de

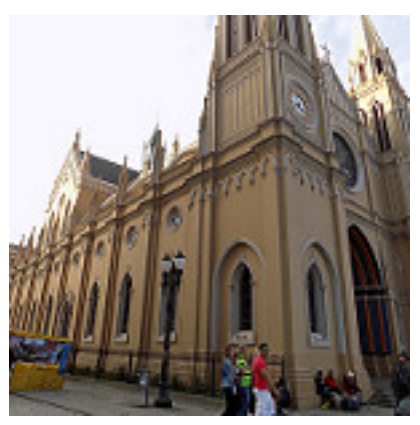

creyentes.

El texto propone una descripción sobre el grupo religioso, las decisiones metodológicas de la investigación y sus principales resultados.

\section{Palabras clave}

Religión, generaciones, foto elicitación, memoria.

\section{Abstract}

This work originate from a doctoral research about the religious transmission in families and members of the Focolare Movement, with qualitative methodology.

The analytical perspective refers to religion as memory (Hervieu-Léger, 1993) on the reinterpretation of each generation as a way of continuity between past and present, in the relationship between the symbolic and practices; generational conflicts and religious socialization of a line of believers.

The text proposes a description of the religious group, the methodological decisions of the investigation and finally the main results.

Keywords Religion, generations, photo elicitation, memory. 


\section{EL MOVIMIENTO DE LOS FOCOLARES}

En la década del 60 se desarrollan en Europa diferentes movimientos

eclesiales como nuevas formas de asociación al interior de la Iglesia católica (Soneira, 2007) inspirados por el Concilio Vaticano II y como consecuencia de insatisfacción respecto del contexto socio-cultural. Dicho desarrollo está en relación directa con la esperanza de una instancia de renovación de la Iglesia que no podía ser eludida (Guasco, 2001: 73) y que encuentra su momento con el Concilio Vaticano II.

El Movimiento de los Focolares, de quien se ocupa este texto, surgió en Italia durante la segunda Guerra mundial y el papado de Pio XII caracterizado por el aumento de las vocaciones, el asociacionismo y las parroquias como centro de la vida cultural y social.

Está formado por laicos y cuenta con más de 140 mil animadores a nivel mundial (www.focolare.org, 2014). Surgió en el norte de Italia en 1949, fundado por Chiara Lubich quien durante la guerra conduce junto a un grupo de mujeres un trabajo pastoral que se convertirá en los inicios de este movimiento, sumando entre sus adeptos primero a mujeres que también se consagran y viven en la misma casa y, más tarde los hombres.

Al interior del catolicismo italiano representan lo que Garelli denomina "subcultura católica" para la sociedad italiana (Garelli, 2007) referido a los laicos que mantienen una correspondencia entre las creencias y su vida cotidiana, brindan a sus hijos una educación religiosa y participan de una comunidad local de creyentes.

Gracias al impulso del Concilio Vaticano II, los movimientos eclesiales se desarrollaron como un "nuevo modelo de Iglesia" (Soneira, 2007) y los focolares en particular se expandieron geográficamente traspasando las fronteras italianas hacia diferentes naciones.

En la actualidad está presente en 182 países, tiene un centro coordinador en Roma, 11 escuelas de formación para sus miembros y 33 pequeñas ciudades cerradas (en adelante, "ciudadelas") alrededor del mundo.

Las "ciudadelas" son pequeñas comunidades insertas en realidades nacionales específicas inspiradas en las antiguas abadías benedictinas. Al mismo tiempo, constituyen espacios impregnados de las características propias del Movimiento de los Focolares que definen el contexto de las prácticas al interior de la comunidad.

Estas ciudades representan para los miembros del Movimiento el testimonio del modelo de "vida en comunión", como un lugar utópico, modelo máximo de "unidad", que reúne sólo a los focolares. Cada "ciudadela" representan la presencia del movimiento y sus seguidores en realidades nacionales, religiosa y culturalmente diversas.

Asimismo, la ciudadela italiana es uno de los lugares de memoria, de momentos claves en el surgimiento y evolución del movimiento eclesial ya que es la primera y junto con las otras ciudadelas constituyen sitios de inscripción del carisma en las sociedades actuales. 
Surgió en Loppiano (Italia) en 1964 donde en la actualidad viven 900 personas. En Argentina, en cambio, se creó en 1968 en la provincia de Buenos Aires, que alberga a unas 200 personas.

Este grupo religioso se diferencia de otros movimientos eclesiales por el carisma de la "unidad" que se relaciona con el espíritu de la vida en comunidad de los primeros cristianos y la búsqueda de la santidad desde el laicado con la aplicación práctica de las enseñanzas del Evangelio en la vida cotidiana, que la vida en las ciudadelas "materializan".

El Movimiento está integrado por familias, personas individuales y religiosos organizados en grupos denominados "vocaciones"; es decir diferentes denominaciones dentro de la estructura ramificada y flexible que consienten una gama de elección más amplia que va desde la participación ocasional a una adhesión más sostenida. Están divididas según la edad, el género y ámbitos de actividades, que proponen momentos de socialización grupales. De esta manera, el movimiento plantea una estructura base que puede compararse con otros movimientos eclesiales y con formas de organización pastoral tradicionales dentro de la Iglesia como "Acción católica" (jóvenes mujeres, jóvenes varones).

Es importante agregar que como grupo representan una minoría de activistas al interior de los católicos en Italia e Argentina donde se realizó la investigación.

Por otro lado, este grupo que fue uno de los primeros movimientos eclesiales italianos surgido antes del Concilio Vaticano II, se destaca en la actualidad como un grupo con características que pueden definirse transnacionales (Csordas, 2009). Por último, por sus dinámicas se establece como comunidad de sentido que atraviesa la esfera de lo religioso para definirse como un sistema integral en la vida de sus miembros.

A continuación, se describe las técnicas metodológicas implementadas para este trabajo y los criterios de selección del campo de la investigación.

\section{METODOLOGÍA}

Por las dimensiones simbólicas y discursivas de la cotidianeidad, que engloban los interrogantes de investigación, se utilizó una metodología cualitativa (Vasilachis de Gialdino, 2006) se realizó un trabajo etnográfico en dos pequeñas ciudades del movimiento en Loppiano, Italia y Mariapolis Lía en Argentina, entrevistas a familias y testimonios privilegiados que son miembros activos del movimiento.

Las observaciones participantes en las dos ciudadelas del Movimiento permitió explorar más allá de lo familiar, la dimensión comunitaria y transnacional y de participar de actividades como congresos, rituales, jornadas. Con la finalidad de describir la dinámica del Movimiento de los Focolares articulando su dimensión transnacional con lo local de la participación individual de sus miembros. 
En lo específico, en las ciudadelas era interesante indagar cómo funcionaba dicha institución en otro contexto diferente al italiano y se eligió la argentina por el país de proveniencia de la investigadora. De las 3 familias entrevistadas: 2 tienen 2 hijos y 1, 4 hijos. Se realizaron entre 2 y 4 encuentros por familia en las casas y se entrevistó a testimonios privilegiados que son miembros del grupo religioso. La foto elicitación reduce al mínimo las preguntas y se busca que el entrevistado relate el sentido que le otorga a las imágenes a través de la asociación libre, de modo que emerja la experiencia subjetiva de manera espontánea. El uso de la foto como estímulo durante las entrevistas produce una interacción diferente entre el observador y el observado, en el sentido que se pueden acercar las distancias, sea porque no tiene la connotación del lenguaje, sea porque el foco de la comunicación se desplaza del entrevistado a la fotografía (Losacco; Faccioli, 2010).

Fue elegida esta metodología visual pensando en el concepto de memoria como clave de lectura de este trabajo de investigación, donde la memoria se materializa en los álbumes de foto y retrata las generaciones de este espacio singular y contradictorio que es la familia, lugar de las primeras socializaciones. De esta manera, la construcción de la cultura material es un puente entre el pasado y el futuro, retratos de generaciones diversas. Además de su función de inmortalizar los aspectos de la vida familiar y reforzar la unidad del grupo familiar (Bourdieu, 1971).

Asimismo, el uso de las fotografías ha colaborado a conocer la historia de cada familia completando la entrevista, facilitando la narración de las fotografías y generando un clima de relativa intimidad con el entrevistado. La comunicación que se produce, a través de lo que cuentan las imágenes tiene que ser entendido como un plus, son autónomas y distintas a la comunicación verbal de una entrevista.

Los album de familia o las cajas de fotos donde con las imágenes las informaciones se transfieren de generación en generación, como una forma de representación material del significado de pertenencia a una familia, como las fotografías de los ritos de pasaje como el matrimonio, los nacimientos, festividades, etc, presentes en la vida de una familia (Chalfen, 1997).

Algunas de las preguntas de investigación relacionadas con lo visual eran las siguientes: ¿Que relatan las fotos de una familia? ¿Que momentos familiares se representan en las fotos? ¿Que dicen las imágenes de las relaciones de parentela, de los ritos de pasaje, de la vida religiosa? ¿Quién arma el album de familia? ¿Cada cuanto se mira?

A continuación, se reproducen fragmentos de entrevista cuando "relatan" la fotografía, relato considerado como biográfico y donde las fotografías son consideradas como foto estímulo. En la selección se privilegiaron las fotos que hacen referencia a la vida religiosa que destacan el aspecto comunitario de la vida religiosa y la pertenencia al grupo; reflejan parte de la historia del Movimiento de los Focolares y sus lugares de memoria.

Por último, la metodología visual ha permitido establecer en el relato la forma en la cual la familia se representa a sí misma y su memoria religiosa familiar. 


\section{RESULTADOS}

Aquí me referiré especialmente a los resultados de la incorporación de la sociología visual a la investigación empírica mencionada. Se describe el análisis de los datos recolectados, con el anexo de la reproducción de algunas fotografías utilizadas durante las entrevistas y fragmentos de cómo el entrevistado describe la fotografía destacando las características de la comunicacion icónica en la búsqueda de las experiencias subjetivas profundas.

El análisis de las fotografías vistas durante las entrevistas fue organizado en tres núcleos temáticos: sociabilidades, ritos de pasaje y formación en la construcción del pasado familiar religioso de cada familia entrevistada.

Las fotos analizadas y con derecho a reproducción dan cuenta que los entrevistados pertenecen a ambientes parroquiales previos al ingreso al movimiento, provienen de familias católicas y tanto los padres como los hijos han recibido los sacramentos (Foto 1 y 3). A nivel comunitario, destaca a la evangelización, las comunicaciones y el activismo participativo como generadoras de un vínculo de pertenencia al Movimiento que une a las generaciones del grupo creyente como la descendencia de un linaje.

Se tienen en cuenta también los aspectos materiales de los álbumes, quien lo hizo y lo conserva por ser la persona que eligió las fotos con las que quiere recordar el propio pasado familiar. En el caso de la familia 1, el álbum era digital a partir de fotografías y diapositivas escaneadas; que fueron visionadas en orden acronológico cuya selección pertenece al padre de familia. En el caso de las familias 2 y 3 el álbum era material, en ambas el álbum del matrimonio y de cuando nacieron los hijos fueron los álbumes elegidos por los matrimonios para usar en las entrevistas. En particular en la familia 2 se incluyó el álbum de comunión de uno de los hijos y en la familia 3 las fotos de los portarretratos que están en el living de la casa pertenecientes a los matrimonios de tres de sus hijos y álbumes actuales que contenían fotos de cumpleaños actuales con la presencia de los nietos; es decir pertenecientes a los últimos cinco años.

Con respecto a la relación con las fotografías, se demuestra una diferencia en los adultos con relación a las generaciones jóvenes de cada familia donde la cultura de la imagen y las fotografías digitales son una cotidianeidad. Entre los entrevistados de entre 20 y 30 años, las fotos que seleccionaron para las entrevistas estaban relacionadas con los amigos (entre los que se cuentan los amigos del movimiento), del deporte que practican, el hobby, algún viaje y en menor medida las fotografías familiares. En el caso de la entrevista a la hija de la familia 1, muchas de las fotos visionadas eran de los últimos 10 años y algunas coincidían con sus álbumes de la red social facebook.

Por otro lado, en las tres familias la visión de los álbumes de familia es una costumbre que hacían "de vez en cuando" o "cuando los hijos eran chicos". Sin embargo, la hija de la familia 2 (de 31 años y madre de dos hijos) manifiesta que es importante hacerles ella misma el álbum a sus hijos hasta los tres o cuatro años en el que tengan escrito los momentos más importantes de esos primeros años. 
Por su parte, los cónyugues de la familia 3, que son el matrimonio de mayor edad en relación con las otras dos familias comentaban que no tenían muchas fotos de la infancia de sus hijos porque "no es como ahora", haciendo referencia a sus nietos; en ese momento ellos no tenían una cámara de fotos.

Sobre las condiciones de producción de las fotografías puede agregarse que las familias 1 y 2 , tienen muchas diapositivas porque, entre otras cosas, era un medio económico por no tener el costo de impresión.

Las fotos de familia ayudan a reordenar los recuerdos de las personas, de los lugares, de los eventos, de los detalles (Chalfen, 1997). El álbum sirve entonces para recordar los eventos considerados importantes, de consecuencia se incluye en el álbum lo que se quiere recordar en futuro, es decir se construye el pasado (Losacco; Faccioli, 2010).

En las fotos que se reproducen, el matrimonio (Foto 1 y 2) marca el inicio de familia cristiana y la institucionalidad del rito. La comunidad religiosa aparece como testigo de los momentos de la familia como los ritos de pasaje y a la familia como perteneciente al grupo religioso.

Sobre la foto 1 , sus protagonistas dicen lo siguiente:

“Hicieron una fiesta en la puerta de la iglesia, éste ahora es arquitecto, trabaja acá en Padua [...] Ellos eran parte de un grupo musical, habían formado el grupo arcoíris de esta zona..." (Giuseppe - padre familia 2)

“Acá...también los Gen, esta (fotografía) es linda, se ve que cantaron en la puerta de la iglesia, cuando salimos. Fue una sorpresa muy linda..." (Marta - madre familia 2)

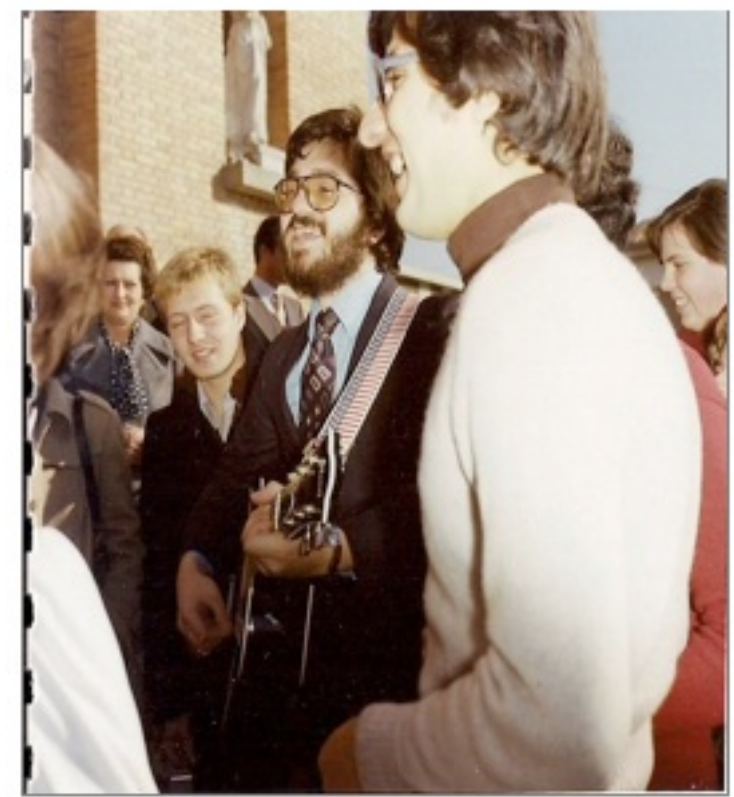

Foto 1.Casamiento familia 2, archivo personal de la familia

En la foto del matrimonio de Marta y

Giuseppe (familia 2) en 1977, dos amigos "Gen" cantan una vez finalizada la ceremonia, mientras los novios saludan en la puerta de la iglesia. Se intuye que los celebrantes están de espaldas al fotógrafo por un fragmento de vestido blanco de la novia que se ve en el margen izquierdo de la fotografía.

La foto remite a un significado religioso en cuanto al rito de pasaje pero también hace referencia al movimiento de los focolares ya que los Gen como grupo lo representan. Asimismo, los novios eran parte del movimiento desde el noviazgo, de modo que el sacramento del matrimonio también simboliza la idea de la consagración espiritual como familia y en el carisma de la unidad, es decir la elección de una vida en comunión 
como pareja.

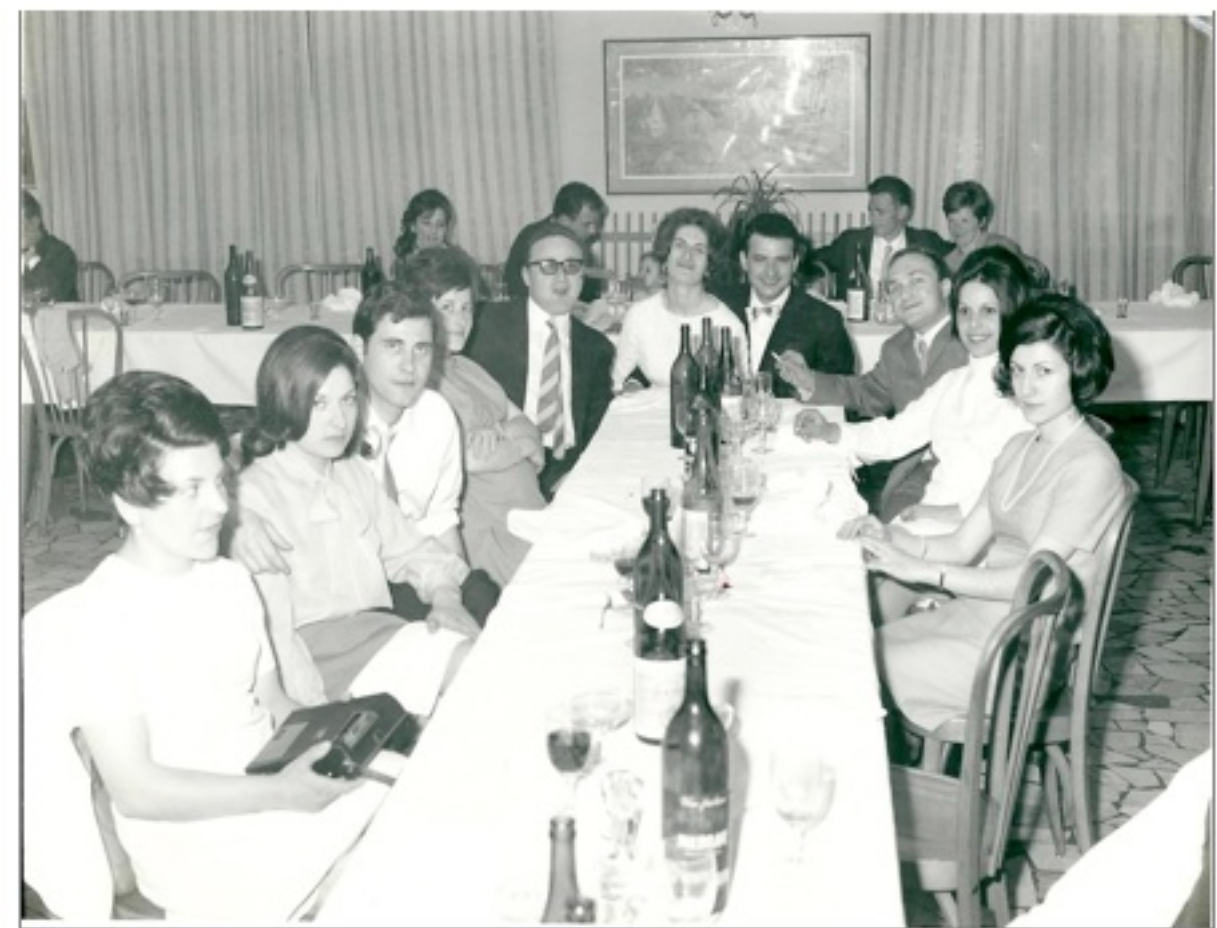

Foto 2. Casamiento familia 3, archivo personal de la familia

La foto 2 es del casamiento de Aldo y Francesca que lo relatan los dos mirando el álbum de esta manera:

Francesca: “acá está la mesa grande de los que fuimos a almorzar más los parientes, los amigos, siempre en una mesa larga, con la torta.

Aldo: ¿cuantos éramos? quien lo sabe!

Francesca: 56, y pagamos 2500 liras por persona.

Aldo: la mesa de los esposos donde estaban sentados también los testigos.

Francesca: estos acá son la hermana de Aldo con el marido que ya falleció, estos de acá son amigos, esta es su cuñada, la prima, éste vive acá cerca,

Aldo: era el intendente que hizo uno o dos mandatos, una linda persona".

Estas personas son los amigos y parientes de la nueva familia que comparten el almuerzo después de la ceremonia, es la tarde del día del casamiento de Francesca y Aldo en un restaurant de la ciudad en la que se casaron. La fotografía parece representar el círculo más cercano de personas que acompañaran la vida familiar de esta pareja, y que quizás estarán presentes en los nacimientos y en los ritos de pasajes de los hijos, en los aniversarios, etc. Por último, el significado de la imagen es festivo, local y al mismo tiempo, la estética de la foto retrata la época que puede leerse desde el vestuario, los peinados y el blanco y negro de la imagen. 
Los álbumes de fotografías son también un archivo visual, una red de relaciones sociales y sirve para conservarlas también cuando las personas crecen, se van o se mueren. Es decir que las fotos refuerzan las pertenencias culturales y la continuidad, documentan los cambios (Chalfen, 1997).

La observancia de los sacramentos está presente en las fotografías (Foto 3) y al mismo tiempo se produce una ampliación de espacios religiosos más allá de las parroquias y se generan otros lugares de agregación del Movimiento ya que el mismo grupo de personas pasa a constituir el círculo de amistades.

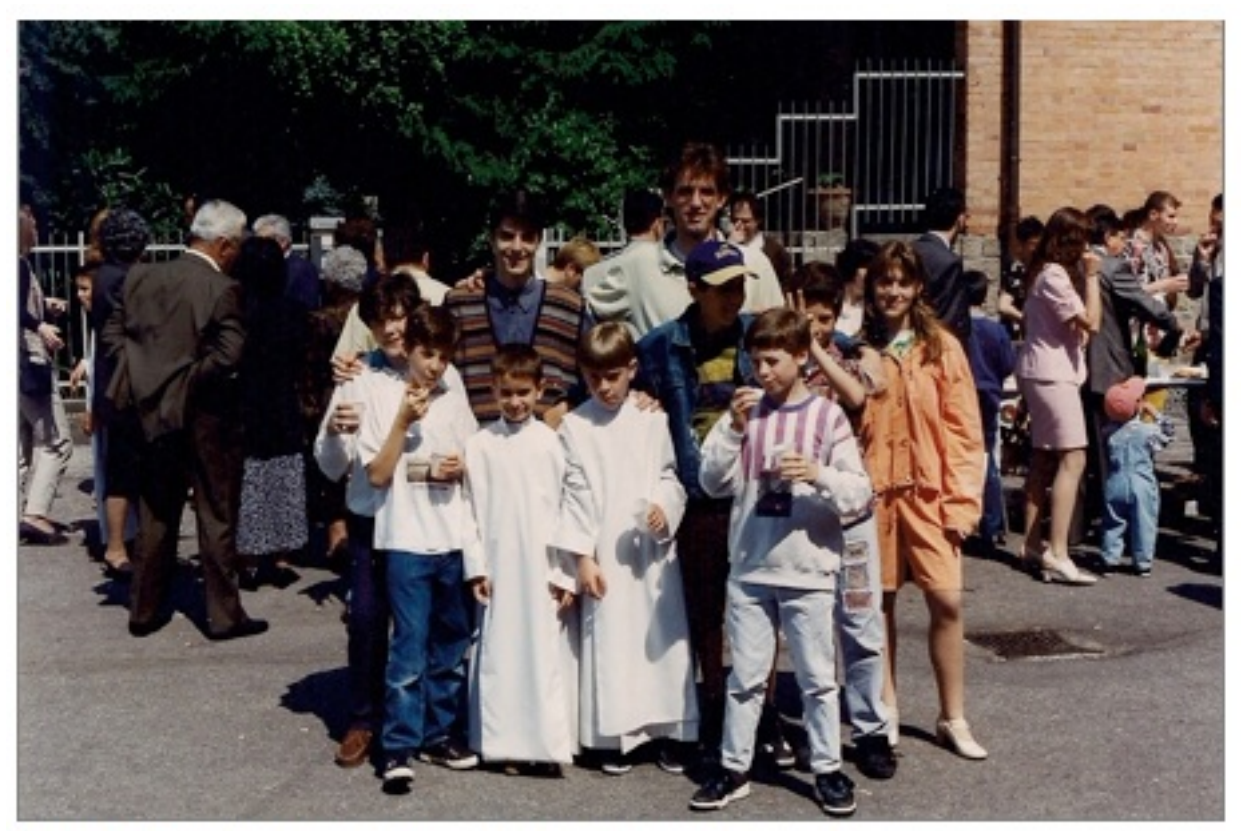

Foto 3. Comunión familia 2, archivo personal de la familia

Esta es la fotografía de la comunión de Paolo en la puerta de la Iglesia con su hermana y amigos, entre ellos amigos "Gen". El relato a continuación es de su madre, que durante la entrevista relata lo siguiente en relación al rito de pasaje de su hijo:

Marta (madre familia 2): "para las comuniones de Vanessa y también de Paolo, de acuerdo con ellos, aunque tenían 10 años, a ellos no les faltaba nada, pedimos a los parientes más cercanos y también a los amigos de no comprarles regalo, le pedimos el equivalente (en dinero), no fue fácil, iniciamos con Vanessa, el equivalente para hacer una adopción a distancia [...] Cada año, lo hicimos con los sacramentos de los dos y después cada año guardábamos plata [...] Esta es la comunión de Paolo, éste sacerdote fue importantísimo para él [...] y acá están los Gen 3, que vinieron a su comunión..."

A través del relato se comprende una manera de vivir los sacramentos en la cuál el regalo es cedido para una adopción a distancia que habían comenzado con la comunión de la hija mayor, tal como lo explica Marta. Asimismo, puede decirse que incorpora la dimensión religiosa pero también la comunitaria ya que refiere a la comunidad local y la vida de parroquia, que es el mismo lugar donde se casaron sus padres y donde fueron bautizados los hijos. 
En relación con el aspecto comunitario, las fotografías dan cuenta de momentos compartidos con el grupo de pertenencia que incluye tanto la comunidad local, cristiana y el grupo religioso que representan los focolares.

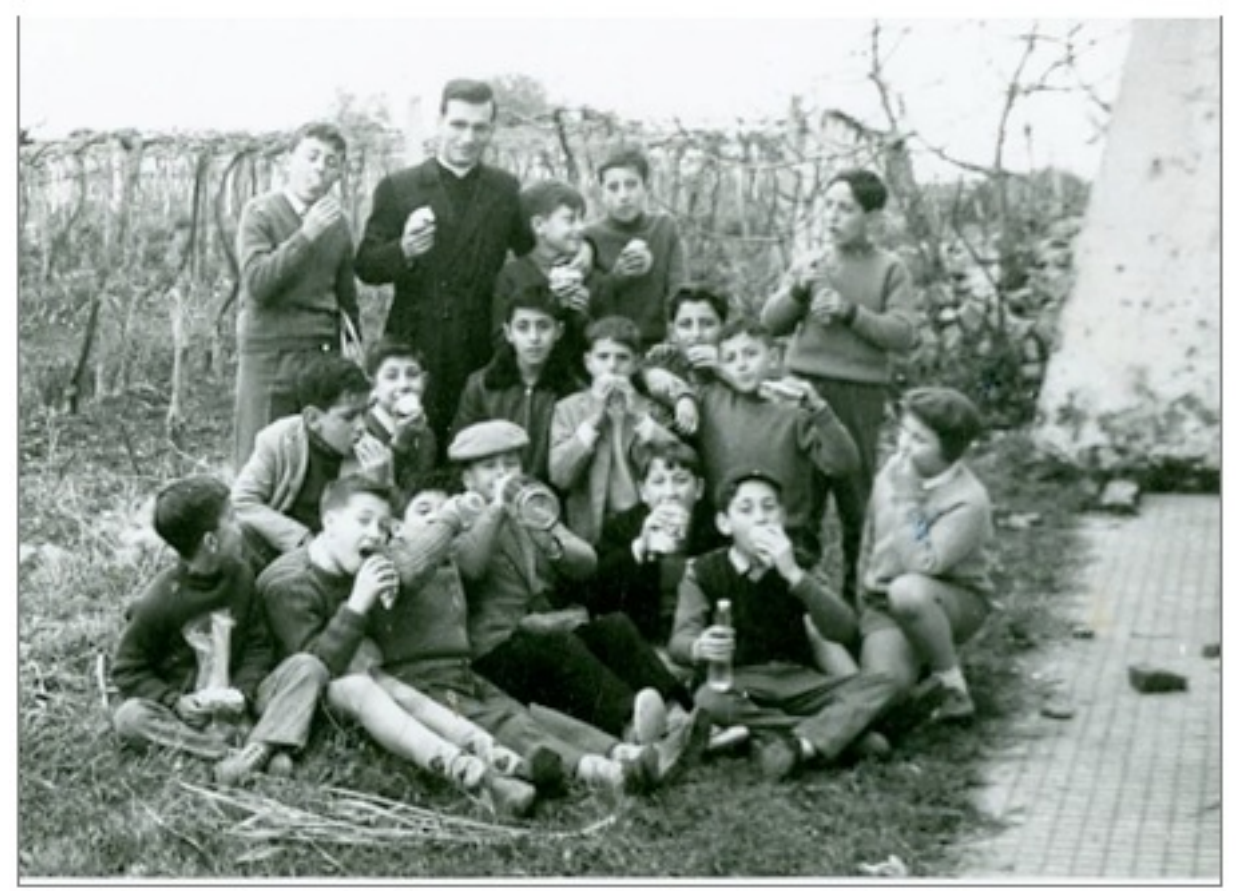

Foto 4. Convivencia, padre familia 1, archivo personal de la familia

Sobre la foto 4, nos dice el entrevistado sobre el recuerdo de una convivencia:

"Esta foto es de un retiro, a las afueras (del pueblo de la infancia) con este sacerdote, era un seminarista, que fue mi primer referente espiritual, tenía 9 años, habíamos ido con el catequismo a hacer un retiro espiritual, no me acuerdo el nombre del lugar exacto [...] Y entonces ahí estábamos, acá estábamos merendando, era el grupo de la Acción católica..." (Romeo, padre familia 1)

Romeo relata lo que muestra la foto, una escena de parte de su educación religiosa en su infancia, se trata del grupo de catequismo que pertenecía a Acción católica y donde aparecen los alumnos que quizás también eran amigos de infancia de Romeo. Sin embargo, en su relato también hace hincapié en la figura de su primer referente espiritual en la persona del sacerdote que vemos en la foto. De este modo, puede decirse que el significado de esta fotografía es religioso pero también es lúdico y comunitario ya que los niños parecen estar divirtiéndose y a su vez, hace referencia a la comunidad de pertenencia al pueblo donde nació Romeo.

La técnica de la foto elicitación permite una conexión con lo emocional de los recuerdos a través de la visualización durante la entrevista. La dimensión discursiva, dice Jedlowski, hace que sea en la narración que se pone en acto la experiencia como vivida de los sujetos. Es decir, la manera en la cual fue interpretado y en la que es recordado, lo que también contribuye a la construcción de un discurso colectivo dentro del cual los relatos de cada uno encuentren lugar (Jedlowski, 2002). 
recuerdan con qué amigos y parientes se compartió ese día, "hacen memoria" de aquello que se creía olvidado y aparece al ver la fotografía relacionado con las experiencias del pasado y los relatos que son parte de la historia familiar.

\section{CONCLUSIONES}

Para finalizar con lo expuesto hasta aquí, sobre la memoria religiosa familiar puede agregarse que si bien el rol de la familia es fundamental en la socialización primaria de los individuos, las entrevistas también destacan las experiencias compartidas con la comunidad cuya dimensión emocional que genera cohesión, integración y pertenencia de los miembros al grupo religioso.

El universo de sentido que representa la pertenencia al Movimiento de los Focolares permite pensarse como un fenómeno más amplio que trasciende lo institucional y familiar.

Por último, a nivel metodológico la incorporación de la técnica de la foto elicitación puede proporcionar un plus ya que la comunicación es propia y diversa a la verbal que se produce en las entrevistas tradicionales y en lo específico es innovadora en los estudios en el ámbito de la sociología de la religión.

\section{REFERENCIAS BIBLIOGRÁFICAS}

BOURDIEU, P. (1971): La fotografia: usi e funzioni sociali di un'arte media. Rimini: Guaraldi. CHALFEN, R. (1997): Sorrida prego! Milano: Franco Angeli.

CSORDAS, T. (2009): Transnational Transcendence. California: University of California Press.

HERVIEU-LEGER, D. (1993): La religión, hilo de memoria. Barcelona: Editorial.

JEDLOWSKI, P. (2002): Memoria, esperienza e modernità. Milano: Franco Angeli.

LOSACCO, G.; FACCIOLI, P. (2010): Nuovo manuale di sociologia visuale. Milano.

SONEIRA, J.A. (2007): “Catolicismo, movimientos eclesiales y globalización en

Latinoamérica". Revista Cultura y Religión. vol. 1, pp. 61-73.

\section{BREVE SEMBLANZA DE LA AUTORA}

Agustina Adela Zaros, es Licenciada en Comunicacion Social por la Universidad Nacional de Rosario (UNR), Magister en Comunicación y Cultura por la Universidad de Buenos Aires (UBA) y Doctora en Ciencias Sociales por la Universidad de Padova (UNIPD). Es docente de Metodología de la Investigación de la Universidad del Salvador (USAL) en Buenos Aires. Sus temas de interes son principalmente la memoria religiosa familiar y la sociologia visual 
Ámbitos. Revista Internacional de Comunicación, n.31, edición de invierno, 2016. Recibido: 26/03/2015 Aprobado: 25/04/2015 